\title{
O papel do odontolegista nas perícias criminais
}

The role of the forensic dentist in criminal reports

\author{
Carine Gomes Valois Coutinho* \\ Caroline Araújo Ferreira** \\ Laís Ramos Queiroz ${ }^{* * *}$ \\ Luanda Oliveira Gomes ${ }^{* *+*}$ \\ Ulisses Anselmo da Silva ${ }^{* * * * *}$
}

\section{Resumo}

Objetivo: o presente trabalho foi realizado com o objetivo de discutir a atuação do odontolegista no âmbito criminal, com intuito de trazer à comunidade acadêmica informações relevantes sobre o assunto. Revisão de literatura: a atuação do profissional especialista em Odontologia Legal restringe-se à análise, perícia e avaliação de eventos relacionados com a área de competência do cirurgião-dentista e é regulada pelos artigos 63 e 64 da Resolução CFO - 63/2005. O odontolegista pode atuar, no âmbito criminal, na identificação no vivo, no cadáver e em perícias antropológicas. A cavidade oral apresenta um grande potencial para a identificação, e a atuação do especialista em Odontologia Legal é de extrema importância, na medida em que o exame de um corpo por meio da boca e das arcadas dentárias pode ser fundamental em uma perícia criminal, sendo a análise odontológica um meio muito utilizado. Considerações finais: o cirurgião-dentista deve ser cuidadoso ao guardar o prontuário, as radiografias e os modelos em gesso dos pacientes, além de anotar todas as informações, pois podem servir futuramente para a identificação positiva de vítimas.

Palavras-chave: Odontolegista. Perícia criminal. Arcada dentária.

\section{Introdução}

A Odontologia Legal é estabelecida pela Resolução CFO-185/93, que, no artigo 54, define-a como uma especialidade odontológica cujo objetivo consiste na pesquisa de fenômenos psíquicos, físicos, químicos e biológicos que podem atingir ou ter atingido o homem, vivo, morto ou sua ossada, e mesmo fragmentos ou vestígios, resultando em lesões parciais ou totais reversíveis ou irreversíveis ${ }^{1}$.

A atuação do profissional em Odontologia Legal restringe-se à análise, perícia e avaliação de eventos relacionados com a área de competência do cirurgião-dentista, podendo estender-se a outras áreas, se as circunstâncias o exigirem ${ }^{1}$.

As áreas de competência para a atuação do especialista em Odontologia Legal incluem: identificação humana; perícia em foro civil, criminal e trabalhista; perícia em área administrativa; perícia, avaliação e planejamento em infortunística; tanatologia forense; elaboração de autos, laudos e pareceres, relatórios e atestados; traumatologia odontolegal; balística forense; perícia logística no vivo, no morto, íntegro ou em suas partes fragmentadas; perícias em vestígios correlatos, inclusive de manchas ou líquidos oriundos da cavidade bucal ou nela

\footnotetext{
Graduanda em Odontologia, Departamento de Saúde, Universidade Estadual de Feira de Santana (UEFS), Feira de Santana, BA, Brasil.

*** Graduanda em Odontologia, Departamento de Saúde, UEFS, Feira de Santana, BA, Brasil.

${ }_{* * * *}^{* *} \quad$ Graduanda em Odontologia, Departamento de Saúde, UEFS, Feira de Santana, BA, Brasil.

**** Graduanda em Odontologia, Departamento de Saúde, UEFS, Feira de Santana, BA, Brasil.

***** Professor do Departamento de Saúde da UEFS, Faculdade de Odontologia, mestre em Odontologia - Deontologia e Odontologia Legal.
} 
presentes; exames por imagem para fins periciais; deontologia odontológica; orientação odontolegal para o exercício profissional e exames por imagens para fins odontolegais (Res. do CFO-185/93) ${ }^{1,2}$.

No âmbito criminal, o odontolegista pode atuar na identificação no vivo, no cadáver e em perícias antropológicas (no crânio esqueletizado). Sua atuação também pode ser dar em perícias de lesões corporais, determinação da idade, perícias de manchas, determinação da embriaguez alcoólica e em outros exames periciais ${ }^{2}$.

Sobre a elaboração de documentos, compete apenas ao perito oficial cirurgião-dentista emitir laudo conclusivo quanto à capacidade ou incapacidade laboral. Ainda, cabe à junta odontológica oficial, sempre que julgar necessário, solicitar pareceres de cirurgiões-dentistas especialistas, ou mesmo de profissionais de outras áreas para esclarecimentos de diagnósticos, para opinar em assuntos de suas competências ou para fundamentar laudos odontopericiais $^{3}$.

Diante disso, este trabalho tem como objetivo discutir a atuação do odontolegista no âmbito criminal com intuito de trazer à comunidade acadêmica informações relevantes sobre o assunto.

\section{Revisão de literatura}

A atuação do odontolegista é regulada pelos artigos 63 e 64 da Resolução CFO - 63/2005, que é intitulada "Consolidação das normas para procedimentos nos Conselhos de Odontologia". De acordo com essa resolução, a atuação do profissional especialista em Odontologia Legal restringe-se à análise, perícia e avaliação de eventos relacionados com a área de competência do cirurgião-dentista, podendo estender-se a outras áreas, se disso depender a busca da verdade, no estrito interesse da justiça e da administração ${ }^{4}$.

Dentre as áreas de competência do odontolegista, vale ressaltar a atuação em perícias criminais, tanatologia forense e identificação humana, meios pelos quais o cirurgião-dentista pode auxiliar a solucionar crimes e identificar vítimas.

\section{Perícia em foro criminal}

O cirurgião-dentista pode atuar em perícias criminais desde que seja solicitado e tenha conhecimento adequado para desempenhar a função de perito. De acordo com Almeida Júnior ${ }^{5}$, perito é a pessoa que realiza exames técnicos de sua especialidade ou competência para esclarecimento de fatos que são objeto de inquérito policial ou processo judicial. O perito é encarregado de servir como auxiliar da justiça, esclarecendo pontos específicos distantes do conhecimento jurídico do magistrado.
Os peritos devem possuir conhecimentos biológicos específicos e noções do pensamento jurídico, visto que auxiliam em uma decisão judicial e seu laudo pode determinar a resolução de um caso. No entanto, a atuação do perito é limitada, pois ele não julga, não defende e não acusa; seu dever é examinar e relatar os fatos necessários para o esclarecimento de um processo ${ }^{2}$.

Os peritos podem ser oficiais e não oficiais. Os peritos oficiais exercem a função por atribuição de cargo público (médicos legistas, peritos criminais e odontolegistas), realizam os exames de corpo de delito e outras perícias requisitadas, cabendo-lhes os exames, a elaboração e a assinatura dos laudos correspondentes. Já os peritos não oficiais são aqueles designados para suprirem a falta de peritos oficiais, ou para substituí-los, quando, por qualquer motivo, estiverem estes impedidos ou impossibilitados de trabalhar ${ }^{2}$.

Entende-se como perícia o conjunto de procedimentos médicos/odontológicos e técnicos que têm como finalidade o esclarecimento de um fato de interesse da justiça. A perícia médico-odontolegal consiste em procedimentos que auxiliam a justiça, tendo como finalidade produzir uma prova que vai ser materializada com o laudo. Tal perícia é praticada por médico ou cirurgião-dentista por meio de exames clínicos, radiográficos, laboratoriais, necroscópicos ou outros ${ }^{2}$.

As perícias criminais são aquelas decorrentes de um evento delituoso, de modo que deve haver um suposto crime. O cirurgião-dentista pode atuar nesses casos, auxiliando no esclarecimento dos fatos, basicamente elucidando a materialidade, a dinâmica e autoria do crime.

Para proceder à perícia, os peritos contam com o exame médico-legal, que é realizado sobre os vivos; exame de necroscopia, feito sobre cadáveres; exame de exumação, realizado mediante a retirada do cadáver da sepultura; e exame laboratorial, para verificar toxicologia e identificação de $\mathrm{DNA}^{2}$.

As perícias odontolegais na área criminal incluem: identificação no vivo (idade não comprovada de delinquentes, marcas de mordida em alimentos ou na vítima), no cadáver (corpos carbonizados, dilacerados, estado avançado de putrefação, afogados, acidentes de massa), antropológicas (no crânio esqueletizado para verificar espécie, sexo, idade, estatura, biótipo); lesões corporais ou perícias de traumatologia; determinação da idade; perícia de manchas (diagnóstico diferencial de manchas de saliva); exame de embriaguez (saliva) ${ }^{6}$.

O odontolegista deve, na perícia, utilizar as vias de cabeça e pescoço e fazer anotações, desenhos, esquemas, fotografias e tudo que for necessário para que o exame fique bem descrito. $\mathrm{O}$ ideal é que não sejam necessários esclarecimentos posteriores, por meio de um segundo exame com o corpo já em de- 
composição ou esqueletizado, na medida em que não trará as mesmas informações.

O exame do cadáver inicia-se, geralmente, analisando as características extraorais. Em seguida, possíveis detritos encontrados na cavidade oral devem ser eliminados. O exame intraoral é, então, realizado, observando-se as condições anátomo-fisiológicas ${ }^{7}$.

Para realizar exame intraoral, o profissional deve utilizar roupas protetoras, instrumentos dentários, material de impressão, material para registro dos dados e uma máquina fotográfica, de forma a recolher toda a informação necessária ${ }^{7}$.

Muitas vezes, porém, o acesso adequado à cavidade oral torna-se difícil e comprometido. Por isso, em alguns casos, recomenda-se a remoção dos maxilares para a realização da autópsia oral, possibilitando, assim, a preservação dos dentes, melhorando a visualização da cavidade oral e facilitando a realização de radiografias ${ }^{7}$.

Todas as informações obtidas no exame dentário devem ser registradas em odontograma próprio, preferencialmente em um modelo internacional, para permitir a troca de dados entre países ${ }^{7}$.

A perícia odontológica tem grande importância em casos em que há corpos carbonizados e mutilados. O exame do DNA é um método de alta confiabilidade, porém possui algumas limitações, como alto custo, possibilidade de degradação e dificuldade de localizar os parentes próximos das vítimas para estabelecer o vínculo genético. A datiloscopia é outro método eficaz e bastante utilizado; entretanto, em algumas situações, os dados das impressões digitais não estão disponíveis no local onde ocorreu o crime, ou ainda, pode ocorrer a destruição das impressões digitais por putrefação ou carbonização, o que inviabiliza o uso desse método ${ }^{7}$.

Sendo assim, o exame de um corpo por meio da boca e das arcadas dentárias pode ser fundamental em uma perícia criminal, já que não existem dentições análogas, os dentes são estruturas altamente resistentes e fornecem informações individuais que podem auxiliar nas investigações.

\section{Identificação humana}

A identificação humana é o processo pelo qual se determina a identidade de uma pessoa, sendo a análise odontológica um dos métodos rotineiramente utilizados, juntamente com outros parâmetros biológicos, como a análise papiloscópica, a análise da íris e a análise genética. Vale ressaltar que a condição em que o corpo da pessoa é encontrado determina a metodologia a ser empregada ${ }^{8}$.

A identificação pode ser feita no vivo, em casos de dentadas ou mordeduras na vítima, no agressor ou em alimentos; no cadáver em adiantado estado de putrefação, quando a identificação datiloscópica é impossível; em carbonizados; em afogados nos quais as polpas digitais tenham sido destruídas; em grandes catástrofes; em casos de dilaceração do corpo e em perícias antropológicas (no crânio esqueletizado) $)^{1}$.

A identificação de cadáveres carbonizados, putrefeitos ou esqueletizados, por meio das características odontológicas, pode ser classificada como uma metodologia do tipo comparativa ${ }^{9}$, pois confronta informações obtidas de documentação ante-mortem com dados coletados post-mortem ${ }^{10} \mathrm{e}$, didaticamente, é dividida em três etapas: exame dos arcos dentários do cadáver, exame da documentação odontológica e confronto odontolegal ${ }^{11}$.

A primeira fase envolve a análise de todas as particularidades odontológicas presentes nos remanescentes dentários e nas demais estruturas do complexo bucomaxilofacial do corpo examinado, relacionadas com a presença e/ou ausência de dentes, cáries, restaurações (faces e materiais), tratamentos endodônticos, próteses, anomalias, giroversões, apinhamentos, etc. No exame da documentação odontológica, são coletadas todas as informações pertinentes ao tratamento efetuado que foram anotadas pelo clínico no prontuário odontológico, associando-as às informações analisadas nos exames complementares (radiografias, fotografias, modelos, dentre outros). A última etapa é a comparação dos dados obtidos nas duas primeiras, considerando-se o mesmo ponto de referência (face, dente) e tendo como base uma análise qualitativa e quantitativa das particularidades odontológicas evidenciadas ${ }^{10,11}$.

Independentemente do método utilizado para identificação do cadáver, os resultados da comparação de ante-mortem e post-mortem levam a uma das quatro situações seguintes: identificação positiva existe singularidade suficiente entre os itens comparáveis nos bancos de dados; identificação presumível (possível) - existem características em comum entre os itens comparáveis nos dados ante-mortem e post-mortem, entretanto, informações oriundas de ambas as fontes podem ser insuficientes; evidência insuficiente para identificação - não existe evidência suficiente disponível; e exclusão das evidências de identificação - existem tanto discrepâncias explicáveis como inexplicáveis entre os itens comparáveis nos dados ante-mortem e post-mortem ${ }^{12}$.

A Odontologia Legal é útil na identificação de vítimas mortais, principalmente nas situações de catástrofes e de conflitos armados que ocorrem frequentemente, na identificação de agressores em processos criminais, passando por avaliação e reparação de danos corporais, e até na identificação de alguns tipos de intoxicações ${ }^{7}$. 


\section{Recursos odontológicos para identificação humana}

\section{Utilização de registros odontológicos}

A documentação produzida em decorrência dos atendimentos odontológicos, geralmente, possui finalidade clínica e propicia ao profissional, a qualquer momento, a consulta sobre o estágio em que se encontra o tratamento de seu paciente, bem como a análise dos procedimentos efetuados ${ }^{10}$. Além da possibilidade de acompanhamento clínico, a documentação serve como prova passível de ser utilizada com finalidade jurídica ou perícia ${ }^{13}$, como imputação de erro profissional e identificação humana ${ }^{14}$, utilizando-se as informações registradas em fichas clínicas, podendo estar associadas a exames radiográficos, modelos de gesso ou imagens intrabucais ${ }^{10}$.

O cirurgião-dentista deve ser detalhista ao registrar dados referentes à identificação do paciente, anamnese, exame físico geral, extra e intrabucal com preenchimento de odontograma (ausências dentárias, restaurações, tratamentos endodônticos, implantes, giroversões, próteses, dentre outras características), plano de tratamento com opções terapêuticas e valores correspondentes, bem como no que concerne à evolução do tratamento. As anotações presentes em fichas clínicas sobre os procedimentos efetuados, associados aos materiais restauradores e às particularidades morforradiográficas dos elementos dentários e áreas circundantes, podem permitir uma identificação positiva de vítimas ${ }^{10,11}$.

Em situações nas quais os vestígios humanos tornam-se escassos, a identificação por meio dos elementos dentários justifica-se, dentre outros fatores, por estes apresentarem inúmeras características peculiares, que tornam impossível a existência de duas pessoas com as mesmas características, mesmo os gêmeos monozigóticos. Os elementos dentários e as estruturas de suporte podem fornecer diversos dados sobre o cadáver e restos cadavéricos, como a espécie, a estatura, fenótipo, genótipo, gênero e idade, estigmas resultantes de profissões ou hábitos pessoais, entre outros ${ }^{7,10}$. Além disso, os dentes e materiais odontológicos possuem considerável resistência física e química à ação do calor, de traumatismos e alguns agentes químicos ${ }^{7,10,11}$.

A resistência dos dentes e dos materiais restauradores é fator que viabiliza a utilização do método odontológico nas identificações post-mortem, principalmente nos corpos carbonizados e/ou calcinados, putrefeitos e esqueletizados. Com efeito, a indestrutibilidade é uma característica que confere maior resistência ao dente do que ao próprio osso a altas temperaturas $\left(600-650^{\circ} \mathrm{C}\right)^{8}$.

Tendo em vista a diversidade de procedimentos reabilitadores que podem ser efetuados durante a prática clínica, torna-se importante que o cirurgião-dentista esteja atento para o correto registro, acondicionamento e arquivamento das peças que compõem a documentação odontológica: o prontuário odontológico, exames por imagem, modelos de gesso e fotografias ${ }^{14}$. Além disso, marcas para identificação em próteses dentárias são importantes porque, ainda que possam ser obtidos, os registros odontológicos de um paciente edêntulo têm chances de não reproduzir o estado atual dos rebordos e osso alveolar. Informações comumente utilizadas para marcas de identificação em próteses dentárias removíveis incluem o nome da pessoa, número da carteira de motorista e/ou outra informação numérica ${ }^{12}$.

Por saber da importância clínica e legal do prontuário odontológico para resguardar o exercício da Odontologia, o CFO disponibiliza um modelo de prontuário, devendo o cirurgião-dentista observar o seu conteúdo e adaptá-lo à sua rotina clínica ${ }^{10}$.

\section{Marcas de mordida}

A Odontologia Legal é uma ciência que coloca seu conhecimento e sua experiência à disposição da justiça. Um importante campo de estudo e análise nessa especialidade é o reconhecimento e a interpretação de sinais e lesões produzidas por mordidas humanas em alimentos e na pele ${ }^{1}$.

A ciência da identificação de marca de mordida pode ser usada para vincular um suspeito a um crime. Essa análise pode elucidar o tipo de violência e o tempo decorrido entre a sua produção e identificação, o que permite mostrar se a marca foi produzida em vida ou pós-morte e, no caso de várias mordidas, identificar a sua sequência. Embora nem toda marca de mordida apresente quantidade suficiente de detalhes, em situações em que estes existem, a identificação das marcas pode ser extremamente útil para estabelecer uma ligação entre a pessoa mordida e o mordedor ou excluir os inocentes ${ }^{15}$.

A dentição humana possui uma singularidade de indivíduo para indivíduo, ou seja, é única e possui diferenças entre as pessoas. Até mesmo nos casos de gêmeos homozigóticos, diferenças são observadas, de acordo com estudos que comprovaram não haver dois indivíduos com a mesma dentição ${ }^{16}$.

A marca de mordida constitui uma lesão produzida pelos dentes humanos e/ou animais, na pele, em alimentos, vestuário ou em outro tipo de objeto, que resulta da aplicação de forma acentuada dos dentes numa base que é passível de ser deforma$\mathrm{da}^{16}$. Geralmente, são observadas em casos de abuso sexual, homicídios, violência doméstica, assaltos, abuso infantil, entre outros ${ }^{17}$.

O recolhimento das impressões da marca da mordida deve ser feito por um odontolegista ou com a sua supervisão. A tomada das impressões é realizada por meio dos polivinilsiloxanos, que são 
materiais de eleição pela estabilidade dimensional. Materiais como alginato não são recomendados devido aos problemas com sua estabilidade. Os modelos deverão ser obtidos por meio de gesso tipo IV ${ }^{16}$.

O protocolo para análise de comparação de marcas de mordida é feito por meio de duas categorias. A primeira refere-se às mensurações de locais específicos, como distância intercanina, chamada de análise métrica. Os dentes anteriores são os mais comumente observados nas marcas de mordida, mas podem ser encontradas, eventualmente, marcas de pré-molares e molares, sendo a distância intercanina muito significativa nesse processo de identificação ${ }^{5,18}$.

A segunda categoria do protocolo para análise de comparação de marcas de mordida refere-se ao emparelhamento físico, também denominado de comparação da forma da injúria ou associação padrão. A associação padrão tem como principal instrumento a sobreposição das imagens. Diversas técnicas de sobreposição utilizam a imagem do objeto conhecido diretamente sobre a imagem do objeto em questão, avaliando os pontos coincidentes e os divergentes ${ }^{18}$.

A análise das marcas de mordida pode ser feita por meio das suas evidências físicas e biológicas. No que diz respeito às evidências físicas, seu estudo contempla a comparação das características individuais do suspeito com a marca de mordida presente na vítima. A análise da evidência biológica, por sua vez, é realizada por meio da saliva existente no objeto que foi alvo da agressão, registrando-se que uma marca de mordida é acompanhada pela presença de saliva ${ }^{16}$.

A tecnologia pode ser utilizada para ajudar nas investigações criminais por meio de reprodução de objetos mordidos nas cenas de crimes. Quando a moldagem do local da marca da mordida é impossibilitada (marcas de mordida em alguns tipos alimentos), a reprodução desses objetos pode ser feita utilizando-se a prototipagem rápida. Além disso, os avanços tecnológicos podem ser empregados para a identificação do agressor por meio da análise do DNA presente na saliva encontrada na marca da mordida $^{18}$.

O conhecimento da análise das marcas de mordida por parte do odontolegista é de extrema importância no âmbito criminal. Essa é uma ferramenta interessante que pode ser utilizada pelo odontolegista em investigações criminais.

\section{Queiloscopia}

A queiloscopia é o estudo das impressões labiais com base em características como espessura e disposição das comissuras dos lábios. O lábio possui marcas exclusivas de uma pessoa, permanentes e imutáveis, assim como a impressão digital, por isso a importância desse tipo de estudo ${ }^{19}$. Acredita-se que apenas as patologias capazes de causar perdas substanciais de tecido mole e, assim, alterar as impressões labiais impossibilitam esse método ${ }^{13,19}$.

Todas as cópias labiais são importantes, mesmo que não sejam visíveis como em uma marca de batom. O vermelhão do lábio possui glândulas salivares menores e glândulas sebáceas que, juntamente com o efeito lubrificante da língua, podem gerar impressões invisíveis ou latentes, as quais têm sido de extrema importância para se chegar à resolução final de um crime. Pode-se facilmente identificar esse tipo de impressão labial com o uso de técnicas fluorescentes ${ }^{19}$.

\section{Rugoscopia palatina}

A técnica de rugoscopia palatina é o estudo baseado nas rugas palatinas (forma, tamanho e posição), levando em conta que aspetos como comprimento, orientação e configuração variam de forma significativa em indivíduos diferentes ${ }^{21}$. Por serem imutáveis, em condições normais, por toda a vida, inclusive até certo período após a morte, as rugas palatinas são eficientes na identificação humana em cadáveres recentes, mas não correspondem a uma técnica útil na investigação de suspeitos na cena de um crime. Entretanto, alguns eventos, como extrema sucção digital e constante pressão devido ao tratamento ortodôntico, podem provocar alterações nos padrões das rugas palatinas ${ }^{20}$.

A cavidade oral possui grande potencial para a identificação, mas, no caso de vítimas desdentadas, limitam-se os recursos para identificação na Odontologia Legal, tornando as rugosidades palatinas um dos únicos elementos disponíveis ${ }^{20}$.

A rugoscopia palatina como sistema de classificação foi proposta em 1930 pelo pesquisador espanhol Trobo-Hermosa ${ }^{20}$, mas várias formas de classificação foram sugeridas nos anos seguintes. Uma delas é a elaborada por Cormoy, que criou um sistema que classifica as rugas palatinas, de acordo com as suas dimensões, em três categorias: ruga principal (acima de $5 \mathrm{~mm}$ ), ruga acessória (variando de 3 a $4 \mathrm{~mm}$ ) e fragmentos (com menos de $3 \mathrm{~mm}$ ). Aliado com a forma em linha, curva e angulada, aponta-se, também, a origem, a direção de cada ruga e a possibilidade de ramificações ${ }^{20}$.

A análise e a classificação das rugas palatinas podem ser feitas de modo a se preservarem as provas que podem ser usadas no futuro, por meio de modelos de gesso ou de fotografia do palato ${ }^{20}$ registrados ante-mortem ${ }^{21}$.

\section{Análise genética no âmbito forense}

Com os avanços da biologia molecular, a análise do DNA em amostras forenses tem sido crescentemente utilizada nos processos de identificação hu- 
mana, e a Odontologia Legal vem participando cada vez mais desses processos, tendo em vista que os dentes (principalmente a polpa dentária) são importantes fontes de $\mathrm{DNA}^{6,21}$.

De acordo com Silveira ${ }^{6}$, os métodos de análise de DNA vêm sendo utilizados mundialmente para solucionar identidades em crimes violentos, atentados terroristas, desastres em massa e para encontrar pessoas desaparecidas.

A análise do DNA é feita a partir do perfil genético, que é obtido por meio da decodificação do DNA nuclear ou mitocondrial. Os gêmeos monozigóticos são os únicos que possuem perfis genéticos iguais, portanto, quando estes são suspeitos de um crime, a análise do DNA não pode ser utilizada no esclarecimento dos fatos ${ }^{7}$.

O DNA pode ser recuperado e utilizado a partir de amostras biológicas, como sangue, sêmen, cabelo, ossos, dentes, unhas, saliva, urina e fluídos biológicos ${ }^{7}$. Essa análise pode ser feita até mesmo no elemento dental submetido a altas temperaturas $\left(500^{\circ} \mathrm{C} \text { e } 600^{\circ} \mathrm{C} \text { pelo período de } 60 \text { minutos }\right)^{22}$. Em situações nas quais ocorrem incêndio, explosões, que restringem a recuperação de informações a partir de restos mortais, os dentes apresentam-se como material eletivo para análise de $\mathrm{DNA}^{21}$. Dessa forma, torna-se imprescindível a atuação do odontolegista na coleta do material genético que será analisado.

A análise genética pode, ainda, ser feita por meio da saliva humana, pois o DNA salivar mantém-se estável e pode ser recuperado sobre a vítima viva ou no cadáver, dependendo do tempo em que ocorreu a lesão. A análise da saliva pode ser feita, por exemplo, em casos de violência em que restaram na vítima marcas de mordida. Nessas circunstâncias, o DNA salivar encontrado na marca de mordida pode ser fundamental para a descoberta do agressor. As investigações criminais podem contar, também, com a análise de DNA salivar deixado em objetos e restos de alimentos na cena do crime, o que pode levar à identificação do criminoso ${ }^{6}$.

\section{Considerações finais}

A atuação do especialista em Odontologia Legal é de extrema importância, e a análise odontológica é um meio muito utilizado, sendo o principal uso dessa especialidade voltado à identificação de agressores em processos criminais e vítimas mortais nos casos de catástrofes e conflitos. Os dentes e materiais restauradores têm alta resistência, inclusive a temperaturas elevadas. Além disso, o lábio possui marcas exclusivas do indivíduo, e as rugas do palato são imutáveis durante toda a vida, inclusive até certo período após a morte. Esses são alguns fatores que fazem a cavidade oral apresentar um grande potencial para a identificação. $\mathrm{O}$ cirurgião-dentista deve ser cuidadoso ao guardar o prontuário, as radiografias e os modelos em gesso dos pacientes, cabendo-lhe anotar todas as informações, pois estas podem servir para a identificação positiva de vítimas.

\section{Abstract}

Objective: the present work was conducted with the purpose of discussing the performance of the forensic dentist in the criminal scope, with the intention of exposing the academic community to relevant information about this subject. Literature review: the performance of the specialist in forensic dentistry is restricted to analysis, report, and evaluation of events related to the dentist's area of competence, and sections 63 and 64 of Resolution CFO - 63/2005 regulate it. The forensic dentist may perform in the criminal scope, live identification, as well as on the body, and in anthropological reports. The oral cavity has great identification potential and the forensic dentist performance is very important since examining the body through the mouth and dental arches might be essential for the criminal report, hence dental analysis is widely used. Final considerations: the dentist must be careful in keeping medical records, radiographs, and dental casts of patients by writing down all relevant information, for they may be useful in the future for positive identification of victims.

Keywords: Forensic dentist. Criminal report. Dental arches.

\section{Referências}

1. Silva M. Compêndio de Odontologia Legal. São Paulo: Medsi; 1997.

2. Peres AS, Peres SHCS, Nishida CL, Grandizoli DK, Ribeiro IWJ, Gobbo LG, et al. Peritos e perícias em Odontologia. Revista de Odontologia da Universidade Cidade de São Paulo 2007; 19(3):320-4.

3. Conselho Federal de Odontologia. Resolução CFO- 87, de 26 de maio de 2009.

4. Conselho Federal de Odontologia. Consolidação das normas para procedimentos nos Conselhos de Odontologia. Aprovada pela Resolução CFO 63/2005.

5. Almeida Júnior E, Reis FP, Galvão LCC, Alves MC, Campos PSF. Análise da distância intercanina com relação ao sexo e sua aplicação na identificação e interpretação de marcas de mordida. RPG Rev Pós Grad 2012;19(1):14-20.

6. Silveira EMSZSF. Odontologia legal: a importância do DNA para as perícias e peritos. Saúde, Ética \& Justiça 2006; $11(1 / 2): 12-8$

7. Santos DPS. A perícia médico-dentária na identificação humana [Dissertação de Mestrado]. Porto: Faculdade de Ciências da Saúde, Universidade Fernando Pessoa; 2012.

8. Paranhos LR, Caldas JCF, Iwashita AR, Scanavini MA, Paschini RC. A importância do prontuário odontológico nas perícias de identificação humana. Rev Fac Odontol Univ Passo Fundo 2009; 14(1):14-7. 
9. Silva RF, Prado MM, Barbieri AA, Daruge Júnior E. Utilização de registros odontológicos para identificação humana. Rev Sul-Brasileira de Odontologia 2009; 6(1):95-9.

10. Terada ASSD, Leite NLP, Silveira TCP, Secchieri JM, Guimarães MA, Silva RHA. Identificação humana em odontologia legal por meio de registro fotográfico de sorriso: relato de caso. Rev Odontol UNESP 2011; 40(4):199-202.

11. da Silva RF, Daruge Júnior E, Pereira SDR, de Almeida SM, de Oliveira RN. Identificação de cadáver carbonizado utilizando documentação odontológica. Rev. Odonto Ciênc 2008; 23(1):90-3.

12. Neville BW, Damm DD, Allen CM, Bouquot JE. Patologia oral e maxilofacial. 3. ed. Rio de Janeiro: Elsevier; 2009.

13. Neville BW, Damm DD, Allen CM, Bouquot JE. Patologia oral e maxilofacial. 2. ed. Rio de Janeiro: Guanabara Koogan; 2004.

14. Silva RF, Benta NG, Daruge Júnior E, Prado MM, Melo M. Importância pericial dos registros odontológicos decorrentes de tratamento protético. Revista Odonto 2008; 16(32):137-43.

15. Bhargava K, Bhargava D, Rastogi P, Paul M, Paul R, Jagadeesh HG, et al. Review research paper: an overview of bite mark analysis. J Indian Acad Forensic Med 2012; 34(1):971-3.

16. Almeida CVS. Marcas de mordida e a identificação humana [Dissertação de Mestrado]. Porto: Universidade Fernando Pessoa; 2012.

17. Stravianos C, Kokkos A, Eliades A, Andreopoulos E. Applications of forensic dentistry - part II. Res J Med Sci 2010; $4(3): 187-94$.

18. Nascimento MM, Sarmento VA, Beal VE, Galvão LCC, Marques JAM. Identificação de indivíduos por meio das marcas de mordida em alimentos utilizando a engenharia reversa e a prototipagem rápida: caso simulado. Arq Odontol 2012; 48(3):134-41.

19. Oliveira JA. Determinação das características queiloscópicas dos graduandos de Odontologia da Universidade Federal da Paraíba [Monografia de Graduação em Odontologia]. João Pessoa: Universidade Federal da Paraíba, Centro de Ciências da Saúde; 2010.

20. Tornavoi DC, Silva RHA. Rugoscopia palatina e a aplicabilidade na identificação humana em odontologia legal: revisão de literatura. Saúde, Ética \& Justiça 2010; 15(1):28-34.

21. Gomes IS. A importância da rugoscopia palatina na identificação humana [Dissertação de Mestrado]. Porto: Faculdade de Ciências da Saúde, Universidade Fernando Pessoa; 2012.

22. Santos UDD. Principais meios de identificação humana em Odontologia Legal [Monografia de Especialização em Odontologia Legal]. Contagem: Funorte Núcleo Contagem; 2011.
Endereço para correspondência:

Laís Ramos Queiroz

Rua Rio Parnaíba, 157, Bairro Brasília

44088-312 Feira de Santana, BA

Fone/Fax: (75) 3221-0853/9222-9666

E-mail: lai_queiroz@yahoo.com.br

Recebido: 08/08/2013. Aceito: 19/09/2013. 